\title{
ANALYSIS OF GLUCOSE BY POTENTIOMETRY USING ELECTRODE CARBON PASTE/MOLECULARLY IMPRINTED POLYMER (MIP) WITH METACRYLIC ACID AS MONOMER
}

\author{
H. Darmokoesoemo*, L. Kustyarini, M. Khasanah and H.S. Kusuma* \\ Department of Chemistry, Faculty of Science and Technology, Airlangga University, \\ Surabaya-60115, Indonesia \\ *E-mail: handokodarmokoesoemo@gmail.com; heriseptyakusuma@gmail.com
}

ABSTRACT

The electrode carbon paste molecularly imprinted polymer (MIP) has been developed to analyze glucose by potentiometry. The MIP was made by mixing glucose as a template, methacrylic acid as monomer and ethylene glycol dimethacrylate as a crosslinker with the mole ratio of 1: 4: 12. The electrode made by mixing activated carbon, MIP, and paraffin with the ratio 50: 35: $15(\%, w / w)$ was observed to perform optimally. The results obtained show that analysis of glucose gives optimum results at $\mathrm{pH} 5$ (without the $\mathrm{pH}$ adjustment). The analysis of glucose using electrodes carbon paste/MIP gives Nernst factor is $28.80 \mathrm{mV} /$ decade, the measurement range is $10^{-2}-10^{-5} \mathrm{M}$ and the limit of detection is $5.87 .10^{-5} \mathrm{M}$. In this study can be known that urea did not interfere the analysis of glucose using this method. The accuracy of this electrode is $70.7-129 \%$ and the coefficient of variation is $0.06-0.18 \%$ for the concentration range $10^{-5}-10^{-2} \mathrm{M}$. This electrode showed response time less than 2 minutes and could be used for 145 times.

Keywords: glucose, molecularly imprinted polymer, potentiometry, electrode carbon paste.

(C) RASĀYAN. All rights reserved

\section{INTRODUCTION}

Diabetes mellitus is a disease in which the body cannot control blood sugar levels automatically. Pancreas in the healthy body will release the hormone insulin, which the function of hormone insulin is to transport sugar through the blood to the muscles and tissues of the body to supply energy. ${ }^{1}$ The impact of excess sugar, or hyperglycemia, namely glikosuria which can lead to changes in fat metabolism. On the other hand, the impact of the shortage of blood sugar levels (hypoglycemia) cause health problems such as hypoglycemia (excess insulin). ${ }^{2}$

Glucose levels can be analyzed using several methods including spectrophotometry ${ }^{3}$, high-performance liquid chromatography (HPLC) ${ }^{4}$ and liquid chromatography-mass spectroscopy (LC-MS) ${ }^{5}$. Analysis of glucose as reducing sugar performed by the Nelson-Somogyi method by spectrophotometry. The disadvantages of this method are less selective because the reagent can give a positive response to reducing compound other than glucose such as fructose and galactose. ${ }^{3}$ Ratnayani et $a l .{ }^{4}$ in his study analyzing glucose and fructose in samples of cottonwoods honey and longan honey with HPLC method. The method shows more specific results than other methods in determining glucose and fructose in the sample. LC-MS method for the analysis of glucose showed high selectivity, but operational costs are also quite high. ${ }^{5}$ In addition, glucose can be analyzed using microwave-assisted extraction method. This method has the potential to be developed considering the time required for the analysis is very fast. But in the analysis of glucose, this method still needs to be validated using procedure that is relatively more complicated when compared with other methods such as potentiometry. ${ }^{6,7}$

In this study, an alternative method was developed for the analysis of glucose that is simpler and cheaper but still sensitive that use potentiometric techniques through the development of the working electrode. One of the materials used to modify the electrode has been developed which is a molecularly imprinted polymer (MIP). 
Molecularly imprinted polymer (MIP) is a technique in the manufacture of polymers that are specific to a particular compound. ${ }^{8}$ The advantages of MIP are had high selectivity for capturing the target analytes, very stable in organic solvents, $\mathrm{pH}$, and extremes temperature. ${ }^{9}$ The advantages of MIP is considered ideal as material in the manufacture of electrochemical sensors. Therefore in this research conducted a synthesis of MIP glucose from methacrylic acid as monomer, ethylene glycol dimethacrylate as cross-linker and glucose as a template.

\section{Materials and Chemicals}

\section{EXPERIMENTAL}

The materials used in this study is glucose, urea, methacrylic acid, chloroform, ethylene glycol dimethacrylate (EGDMA), benzoyl peroxide (BPO), methanol, glacial acetic acid, carbon, solid paraffin, and $\mathrm{Ag}$ wire. All chemicals used have purity degree of pro analysis. The water used is distilled water.

\section{Preparation of Control Polymer (Poly Methacrylic Acid)}

Firstly, methacrylic acid was weighed 0.0688 grams and dissolved with $5 \mathrm{~mL}$ of chloroform in a glass beaker. Furthermore, in another glass beaker was weighed 0.4752 grams of ethylene glycol dimethacrylate (EGDMA) and added 0.2422 grams benzoyl peroxide which was dissolved in $1 \mathrm{~mL}$ of chloroform. The two solutions are mixed and heated at a temperature of $60^{\circ} \mathrm{C}$ without stirring until it forms solid. The next step is drying of solids in the open air. The dried solids are washed with ethanol three times. Then the solids are dried in an oven to obtain polymer powder.

\section{Preparation of Non-Imprinted Polymer (NIP)}

Firstly, methacrylic acid was weighed 0.0688 grams and dissolved with $5 \mathrm{~mL}$ of chloroform and glucose as template was weighed 0.0360 grams and diluted with distilled water in a glass beaker. Furthermore, the solution is mixed. In the different glass, beaker was weighed 0.4752 grams of ethylene glycol dimethacrylate (EGDMA) and added with 0.2422 grams of benzoyl peroxide that was dissolved in $1 \mathrm{~mL}$ of chloroform. In the mixture of methacrylic acid and glucose are added with the mixture of EGDMA and benzoyl peroxide then heated at a temperature of $60^{\circ} \mathrm{C}$ without stirring. The solids that formed then dried in the open air. The solid is subsequently crushed, washed using mixture of acetic acid and methanol with ratio $2: 8$ and dried in open air. ${ }^{10}$

\section{Preparation of Molecularly Imprinted Polymer (MIP)}

Half of NIP obtained from the previous procedure then extracted with $10 \mathrm{~mL}$ of hot water three times. Furthermore, the filtrate separated from the solids using a centrifuge. The resulting solids are then dried in an oven.

\section{Preparation of Carbon}

Carbon chemically activated by immersion in $\mathrm{H}_{3} \mathrm{PO}_{4} 10^{-1} \mathrm{~N}$ for 24 hours. Furthermore, the carbon that has been soaked, filtered using Buchner funnel and washed using distilled water. Washing is done using distilled water until neutral $\mathrm{pH}$ in the filtrate. Carbon that has been filtered and then heated in an oven at a temperature about $60^{\circ} \mathrm{C}$ to obtain dry carbon powder.

\section{Preparation of Working Electrode Carbon Paste/MIP}

The working electrode carbon paste/MIP prepared by mixing paraffin activated carbon and MIP with varying of mass ratio in $1 \mathrm{ml}$ micropipette tip. The mixture of paraffin, activated carbon and MIP is heated to form a paste. Further into the micropipette tip installed $\mathrm{Ag}$ wire that serves as a liaison of electrode and potentiometer. Paraffin is inserted into the micropipette tip to fill three-quarter micropipette tip section, while the remaining empty space in the micropipette tip filled with paste result of mixing between paraffin, activated carbon and MIP (35:50:15 (\%,w/w)) then pressed so that the micropipette tip to be full filled. Furthermore, the electrode surface was rubbed with HVS paper until the surface is smooth. The construction of electrodes carbon paste/MIP can be seen in Figure-1. 


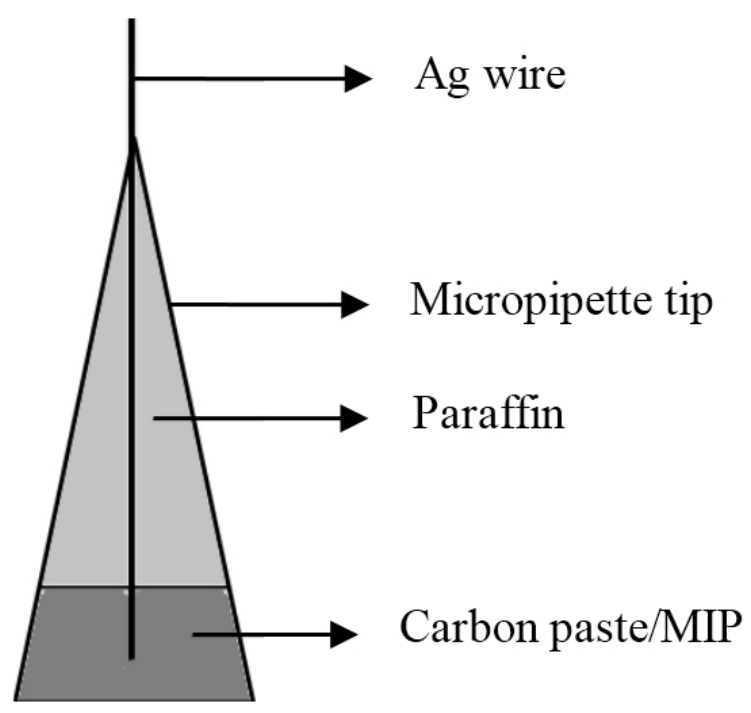

Fig.-1: The construction of electrodes carbon paste/MIP

\section{RESULTS AND DISCUSSION}

\section{Preparation results of molecularly imprinted polymer (MIP)}

In the preparation of MIP is an advanced step of NIP preparation. After obtained yellowish-white powder then conducted extraction of glucose that trapped in the polymer chain to form the glucose mold in the polymers. ${ }^{10}$ The formed bond between monomers and glucose is hydrogen bonding which is easily broken so that glucose is easily extracted from the polymer chain. ${ }^{11}$ The estimation of formed mold on the MIP can be seen in Figure -2.

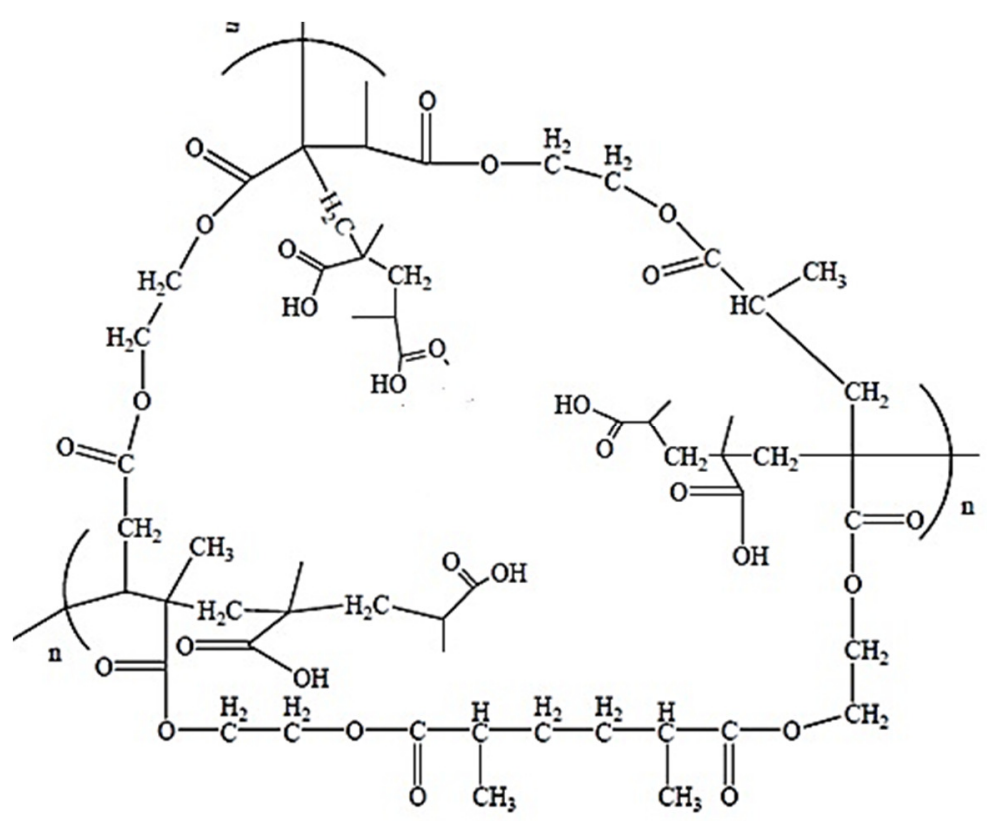

Fig.-2: The estimation of formed mold on the MIP $\mathrm{M}^{10}$ 


\section{The Performance Comparison of Electrodes Carbon Paste/MIP and Validity of Potentiometric Method}

The results of this study include the validity of the method and the performance of electrode carbon paste/MIP by potentiometric compared with the results of previous studies such as analysis of glucose using electrode carbon paste/zeolite ${ }^{12}$ and analysis of glucose using electrode carbon paste/MIP with melamine chloranil as monomer ${ }^{13}$. The results of method validity and the performance of the electrode can be seen in Table-1.

Table-1: The comparison of the validity of some methods and the performance of the electrodes on the analysis of glucose by potentiometric

\begin{tabular}{l|l|l|l}
\hline Parameter & $\begin{array}{l}\text { Electrode carbon } \\
\text { paste/zeolite }\end{array}$ & $\begin{array}{l}\text { Electrode carbon } \\
\text { paste/poly } \\
\text { chloranil }\end{array}$ & $\begin{array}{l}\text { Electrode carbon } \\
\text { melamine } \\
\text { paste/poly } \\
\text { methacrylic acid }\end{array}$ \\
\hline Limit of detection & $5.62 \times 10^{-5} \mathrm{M}$ & $8.75 \times 10^{-5} \mathrm{M}$ & $5.87 \times 10^{-5} \mathrm{M}$ \\
\hline Measurement range & $10^{-4} \mathrm{M}-10^{-2} \mathrm{M}$ & $10^{-4} \mathrm{M}-10^{-1} \mathrm{M}$ & $10^{-5} \mathrm{M}-10^{-2} \mathrm{M}$ \\
\hline Response time (sec) & - & $85-17$ & $62-45$ \\
\hline Accuracy (\%) & $88.64-94.63$ & $51.8-141$ & $70.7-129$ \\
\hline Precision (\%) & $0.42-2.20$ & $0.52-0.86$ & $0.06-0.18$ \\
\hline Selectivity & $\begin{array}{l}\text { More selective for } \\
\text { glucose than ascorbic } \\
\text { acid and uric acid }\end{array}$ & $\begin{array}{l}\text { More selective for } \\
\text { glucose than ascorbic acid } \\
\text { and uric acid }\end{array}$ & $\begin{array}{l}\text { More selective for } \\
\text { glucose from the urea }\end{array}$ \\
\hline $\begin{array}{l}\text { Life time (the amount of } \\
\text { usage) }\end{array}$ & $>63$ & 96 & 145 \\
\hline
\end{tabular}

From Table-1 it can be seen that the potentiometric method with different components of MIP has some advantages such as wide measurement range, precision and lifetime. The measurements range of electrode carbon paste/polymethacrylic acid is wider $\left(10^{-5}-10^{-2} \mathrm{M}\right)$ than the electrode carbon paste/zeolite, precision is quite good and the lifetime is quite long (145 times of usage).

Based on the development of electrode carbon paste/MIP with methacrylic acid as monomer gives Nernst factor is 28.80 and measurement range is $10^{-5}-10^{-2} \mathrm{M}$. In this study, the value of $K_{\mathrm{ij}}>1$ so it can be said that the urea does not interfere in the analysis of glucose.

\section{CONCLUSION}

The measurement of glucose solution is conducted potentiometrically using electrodes carbon paste/MIP with the composition of activated carbon, paraffin and MIP are $50: 35: 15(\%, \mathrm{w} / \mathrm{w})$. The analysis of glucose using electrodes carbon paste/MIP gives the value of Nernst factor is $28.80 \mathrm{mV} /$ decade with linearity $(r)$ is 0.9917 . The resulting measurement range is $10^{-5}-10^{-2} \mathrm{M}$, while the glucose detection limit is $5.87 .10^{-5} \mathrm{M}$. The selectivity is stated with $K_{\mathrm{ij}}$ that give value for urea solution $10^{-2} \mathrm{M}$ is 0.086 . From the value of $K_{\mathrm{ij}}$, can be concluded that the electrode is selective towards the glucose. The resulting accuracy of the glucose solution with concentration $10^{-5}-10^{-2} \mathrm{M}$ is $70.7-129 \%$. While the precision is stated by the coefficient of variation for the glucose solution with concentration $10^{-5}-10^{-2} \mathrm{M}$ is $0.06-0.18 \%$. This electrode has an average response time less than 2 minutes and the lifetime of electrode up to 145 times of usage.

\section{REFERENCES}

1. L. Sustrani, Hypertension (in Bahasa Indonesia), PT Gramedia Pustaka Utama, Jakarta (2006).

2. R.K. Murray, D.K. Granner, P.A. Mayes and V.W. Rodwell, Harpers Biochemistry, 24th edition, Appleton and Lange, Stamford, Connecticut, United States (1996). 
RASĀYAN J. Chem.

Vol. 10 | No. 1 |64-68 | January - March | 2017

3. S. Sudarmadji, B. Haryono and Suhardi, Analysis procedure for foodstuff and agriculture (in Bahasa Indonesia), Liberty, Yogyakarta (1997).

4. K. Ratnayani, S.N.M.A.D. Adhi and I.G.A.M.A.S. Gitadewi, Journal of Chemistry, 2(2), 77 (2008).

5. M.A. Kamal and P. Klein, Saudi Journal of Biological Sciences, 18(1), 17 (2011).

6. H.S. Kusuma and M. Mahfud, Journal of Applied Research on Medicinal and Aromatic Plants, Articles in Press (2016). DOI: 10.1016/j.jarmap.2016.08.002

7. H.S. Kusuma and M. Mahfud, RSC Advances, 7(3), 1336 (2017). DOI: 10.1039/C6RA25894H

8. H. Yan and K.H. Row, International Journal of Molecular Sciences, 7(5), 155 (2006).

9. L. He, Y. Su, Y. Zheng, X. Huang, L. Wu, Y. Lui, Z. Zeng and Z. Chen, Journal of Chromatography $A, \mathbf{1 2 1 6}(34), 6196$ (2009).

10. R. Liang, R. Zhang, and W. Qin, Sensor and Actuators B: Chemical, 141(2), 544 (2009).

11. B.B. Prasad and D. Lakshmi, Electroanalysis, 17(14), 1260 (2004).

12. B. Ilmiyah, Modification of electrodes carbon paste-imprinted zeolite as potentiometry sensor of blood glucose (in Bahasa Indonesia), Thesis, Faculty of Science and Technology, Airlangga University, Surabaya (2015).

13. I. Noryani, Development of electrodes carbon paste/molecularly imprinted polymer (MIP) with melamine and chloranil as monomer for potentiometry sensor of glucose (in Bahasa Indonesia), Thesis, Faculty of Science and Technology, Airlangga University, Surabaya (2015).

[RJC-1559/2017] 